\title{
Community Participation in Wildlife Conservation in Amboseli Ecosystem, Kenya
}

\author{
Michael L. Kipkeu ${ }^{1,}$ Prof. Samson W. Mwangi ${ }^{1}$ Dr. James Njogu ${ }^{1}$ \\ ${ }^{I}$ (Department of Peace, Security and Social Studies, Egerton University, Kenya)
}

\begin{abstract}
Amboseli National Park is regarded as one of the most economically significant parks owing to high tourist visitation and revenue streams. Despite the economic significance of Amboseli National Park, the wildlife dispersal areas outside the park boundaries are shrinking at an alarming rate due to changing land use activities and a growing human population pressure, aggravating human -wildlife conflicts as well as creating unviable ecosystem for wildlife. The park cannot support the current wildlife populations without the dispersal areas offered by the community land. The ecological limitation of the park calls for the management of wildlife resource in the ecosystem to be inclusive and involve the local communities. This study therefore aimed to provide these linkages and fill the existing gap by examining modalities for enhancing community participation in wildlife conservation in Amboseli Ecosystem informed by Social Exchange Theory and supported by the General Systems Theory.
\end{abstract}

Keywords: Benefit Sharing, Community, Ecosystem, Land Tenure, Focus Group

\section{Introduction}

This study examined opportunities for enhancing community participation in wildlife conservation by sustaining community rights and benefits sharing in the Amboseli ecosystem. It is apparent that conflicts in the developing world between wildlife conservation objectives and indigenous livelihood practices have severely threatened the sustainability of each enterprise [1]. In East Africa, most important protected areas are found adjoining pastoral land use systems. Extensive forms of land use are to a greater degree compatible with wildlife management where wildlife, livestock and local resources users are part of a complex social and natural resource management system. In Kenya, most of our national parks and reserves are heavily dependent on surrounding community and private owned lands for their ecological survival and integrity. Others rely on such lands for corridors and dispersal areas. These national parks and reserves and the larger ecosystems are already under threat with significant loss of biodiversity and have attracted a wide range of competing and conflicting land uses due to lack of systematic land use planning and unplanned developments - cultivation, human settlements and tourism facilities development. This is the case with Amboseli. This has resulted in loss of habitats, land fragmentation, blockage of migratory corridors and increasing human wildlife conflict

The Amboseli ecosystem comprises Amboseli National Park (ANP), six surrounding group ranches, and small individual ranches covering an area of 5,700 sq. km. The National Park covers $392 \mathrm{sq} . \mathrm{km}$ or about $7 \%$ of the ecosystem. The park serves as a dry season concentration area due to its series of swamps [2]. The park is however too small and is therefore dependent on the surrounding community lands for wildlife dispersal. If the ecosystem is to continue supporting viable populations of wildlife and retain its ecological character, the Park must be maintained and the surrounding strategic dispersal areas protected.

This ecosystem is renowned for its abundance and diversity of wildlife; however, the ANP is too small, and not viable to maintain the current wildlife populations which rely on larger ecosystem than protected within the national park. The threats against wildlife in Amboseli ecosystem continue to escalate due to an increase in habitat fragmentation, change in land use and human population pressure in areas outside the park. Loss of wildlife habitat outside the protected area should be halted to ensure the viability and large abundance and diversity of species; maintain existing and provide additional new areas for the growing tourism industry to operate; and sufficient space to provide resilience to critical ecosystems as well as species as climate changes and climate variability poses new threats.

Securing more space for wildlife conservation without compromising the livelihood of the local population will entail a series of strategies that this study will attempt to explore. It is a fact that the existence and ecological integrity of the Amboseli ecosystem is increasingly threatened. To assure viability, it will be necessary to explore modalities for enhancing community participation in wildlife conservation by sustaining community rights and benefit sharing in the Amboseli ecosystem.

Amboseli National Park is a perfect example of the problems of conserving the spectacular large mammal communities found in a protected area. As in many other parks, Amboseli's wildlife migrates seasonally beyond the park boundaries, in this case onto land owned by Maasai pastoralists. Viable approach lies in greater efforts to identify ways of reconciling wildlife conservation and alternative land uses throughout the ecosystem [3]. 
There is an increasing realization that, the management of wildlife resource needs to be inclusive and involve the local communities. Conservation authorities are increasingly becoming aware of the need to involve local communities in managing natural resources to safeguard and secure more space for wildlife conservation [4]. Similarly, the local communities are now seeking ways of getting benefits from the wildlife resources on their lands particularly through wildlife-based eco-tourism ventures that have the potentials for direct benefits.

\section{Methodology}

This study was conducted through a cross sectional survey in Kimana/ Tikondo and Olgulului/Ololarrashi group ranches situated within the ecosystem. This type of design gathers information from selected population and it is useful in assessing practices, attitudes, knowledge and beliefs of a population in relation to a particular event. The results from this survey will not only give an indication of the magnitude of the problem in Amboseli at this particular point in time, but also provide a basis for designing appropriate measures to ensure community participation in wildlife conservation. This study used semi structured interviews with the household head from each of the two group ranches as stated above. All interviews were conducted with the help of a local research assistant and translator fluent in the local language. The interviews were either conducted in English or in the traditional Maa language depending on the participant's preference and comfort level. Focus group discussions involving a maximum number of twelve and a minimum of eight were used to supplement and verify the data gathered from the interviews. Data collected from different sources was summarized and presented using frequency tables and charts. For the descriptive data, descriptive statistics were used for analysis utilizing frequency distributions, percentages and mean scores.

\section{Results and Discussion}

The broad objective of this study was to examine the modalities for enhancing community participation in wildlife conservation in Amboseli Ecosystem. A ten point Likert scale was used to measure the extent to which the local community was involved in wildlife conservation in this ecosystem where 1-3 represented 'Low' and 4-7 'Moderate' and 8-10 'High'. Selection of the land use types for measurement was informed by both theoretical considerations and descriptions found in the literature. The scores "Low" represented community participation in wildlife conservation to a "Low Extent" (LE), equivalent to 1 to 3.9 on the continuous Likert scale $(1 \leq \mathrm{LE}<3.9)$. The scores of "Moderate" represented community participation in wildlife conservation to a "Moderate Extent" (ME). This was equivalent to 4.0 to 6.9 on the Likert scale $(4.0 \leq \mathrm{ME}<7.9)$. The score "High" represented community participation in wildlife conservation to a "High Extent" (HE). This was equivalent to 8.0 to 10.0 on the Likert scale $(8.0 \leq \mathrm{LE}<10.0)$. Aggregation of community participation in wildlife conservation was carried out to obtain statistics for further analysis. A summary of the descriptive statistics for analysis of community participation in wildlife conservation in the Amboseli ecosystem is presented in Table 1.

\section{Table 1: Community Participation in Wildlife Conservation}

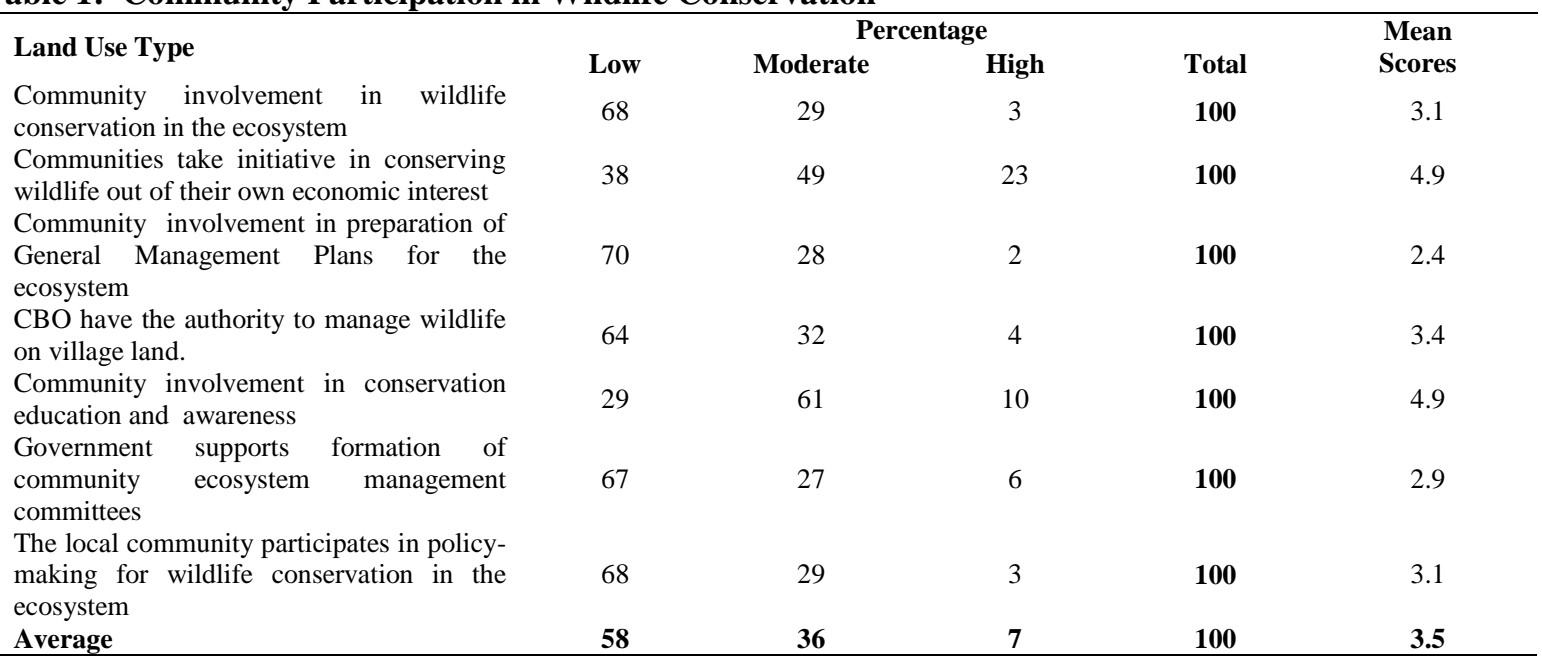

Source: Fieldwork, August 2013

Overall, findings indicate that community participation in wildlife conservation in the Amboseli ecosystem is to a low extent with a composite mean score of $3.5(1 \leq \mathrm{LE}<3.9)$ out of a possible 10 . This study shows that 58 percent, 36 percent and 7 percent of the respondents asserted community participation in wildlife conservation in the Amboseli ecosystem to a low, moderate and high extent respectively. Findings Table 4 
reveals that communities are involved in wildlife conservation in the ecosystem; communities are involved in preparation of General Management Plans for the ecosystem; CBOs have the authority to manage wildlife on village land; Government supports formation of community ecosystem management committees and that the local community participates in policy-making for wildlife conservation in the ecosystem but to a low extent as the mean scores were within this range $(1 \leq \mathrm{LE}<3.9)$ equivalent to 1 to 3.9 on the continuous Likert scale. It was established that communities take initiative in conserving wildlife out of their own economic interest and that communities are involved in conservation education and awareness but to a moderate extent as the mean scores were within this range $(4.0 \leq \mathrm{ME}<6.9)$ equivalent to 4.0 to 7.9 on the Likert scale. This implies that most community needs and aspirations might have been ignored on developing conservation programmes which could lead to difficulties in enforcing conservation policies in the Amboseli ecosystem as the policies may not be respected by local community, illegal activities may become common and/or locals may be dissatisfied with management of the ecosystem.

\section{Relationship between Land Use Types and Wildlife Conservation}

The first specific objective of this study was to examine the effect of land tenure and land use systems on community participation in wildlife conservation in the Amboseli ecosystem. The Pearson's Product moment correlation, which is a non-parametric measure of the strength and direction of association that exists between two variables, was used to measure the existing relationship between land tenure and land use systems and community participation in wildlife conservation in the Amboseli ecosystem.

Table 2: Relationship between Land Tenure and Land use Systems and Community Participation in Wildlife Conservation

\begin{tabular}{lcc}
\hline & & Community Participation in Wildlife Conservation \\
\hline Land Tenure and Land use & Pearson Correlation & $0.480 * *$ \\
Systems & Sig. 2-tailed & .000 \\
& $\mathrm{~N}$ & 100 \\
\hline
\end{tabular}

** Correlation is significant at the 0.01 level 2-tailed.

From the correlations presented in Table 5, land tenure and land use systems $(\mathrm{r}=0.480, \mathrm{P}<.01)$ yielded moderate and significant positive relationships with community participation in wildlife conservation. This implies that the existing land tenure and land use systems moderately influence community participation in wildlife conservation. To confirm the nature of the relationship between land tenure and land use systems and community participation in wildlife conservation, a regression analysis was done and the results are presented in Table 3.

Table 3: Regression results for Land Tenure and Land use Systems and Community Participation in Wildlife Conservation

\begin{tabular}{lccccccc}
\hline & Unstandardized Coefficients & Standardized \\
Model & Coefficients & T & R & $\mathbf{R}^{2}$ & p-value \\
\hline $\mathbf{1}$ & $\begin{array}{l}\text { Std. } \\
\text { Error }\end{array}$ & Beta & & & \\
& $\begin{array}{l}\text { Lanstant) } \\
\text { use Systems }\end{array}$ & 0.082 & 0.493 & 29.403 & & & .000 \\
& 0.191 & 0.041 & 0.272 & -0.763 & 0.391 & 0.153 & .000 \\
\hline
\end{tabular}

Dependent Variable: Community Participation in Wildlife Conservation

From the findings, land tenure and land use systems in the ecosystem negatively influences community participation in wildlife conservation in the ecosystem. The regression results (Table 6) showed that land tenure and land use systems in the ecosystem have a direct effect upon community participation in wildlife conservation in the ecosystem with a positive standardized beta coefficient $(0.272)$. The results show that 15.3 per cent $\left(\mathbf{R}^{2}=0.153\right)$ of the variation in community participation in wildlife conservation in the ecosystem is explained by land tenure and land use systems in the Amboseli ecosystem. However, increased application of the existing the land tenure and land use systems $(\mathrm{T}=-0.763)$ appear not to encourage community participation in wildlife conservation due conflicts with pastoralism (the dominant socio-cultural and economic activity in the Amboseli ecosystem centering on cattle, goat and sheep) and farming. It is therefore appropriate to align these land tenure and land use systems with dimensions of community participation in wildlife conservation to encourage local communities in taking initiatives towards wildlife conservation in the ecosystem.

\section{Implication of Wildlife policies and legal framework on community participation} in wildlife conservation

The second specific objective of this study was to assess the implication of wildlife policies and legal framework on community participation in wildlife conservation in the Amboseli ecosystem. A ten point Likert 
scale was used to measure the extent to which the Kenyan policy and governance practices has affected the community's participation in wildlife conservation in the Amboseli ecosystem where 1-3 represented 'Low' and 4-7 'Moderate' and 8-10 'High'. Selection of the land use types for measurement was informed by both theoretical considerations and descriptions found in the literature.

The scores "Low" represented an item of the Kenyan policy and governance practices perceived to be affecting the community's participation in wildlife conservation in the Amboseli ecosystem to a "Low Extent" (LE), equivalent to 1 to 3.9 on the continuous Likert scale $(1 \leq \mathrm{SE}<3.9)$. The scores of "Moderate" represented an item of the Kenyan policy and governance practices perceived to be affecting the community's participation in wildlife conservation in the Amboseli ecosystem to a "Moderate Extent" (ME). This was equivalent to 4.0 to 7.9 on the Likert scale $(4.0 \leq \mathrm{ME}<7.9)$. The score of "High" represented an item of the Kenyan policy and governance practices perceived to be affecting the community's participation in wildlife conservation in the Amboseli ecosystem to a "High Extent" (HE). This was equivalent to 8.0 to 10.0 on the Likert scale $(8.0 \leq \mathrm{LE}<10.0)$. A summary of the descriptive statistics on the extent to which the Kenyan policy and legal framework has affected the community's participation in wildlife conservation in the Amboseli ecosystem is presented in Table 4.

Table 4: Effect of Kenyan policy and legal framework on community participation in wildlife conservation

\begin{tabular}{|c|c|c|c|c|c|}
\hline \multirow{2}{*}{ Policy Framework } & \multicolumn{4}{|c|}{ Percentage } & \multirow{2}{*}{ Mean Scores } \\
\hline & Low & Moderate & High & Total & \\
\hline Supports formation and operation of group ranches & 16 & 54 & 30 & 100 & 6.94 \\
\hline $\begin{array}{l}\text { Provides guidelines for establishment of community } \\
\text { conservancies }\end{array}$ & 17 & 51 & 32 & 100 & 6.31 \\
\hline $\begin{array}{l}\text { Provides framework for lease agreements for land } \\
\text { management structures in the ecosystem }\end{array}$ & 18 & 49 & 33 & 100 & 6.02 \\
\hline $\begin{array}{l}\text { Provides guidelines for establishment of eco-tourism } \\
\text { ventures }\end{array}$ & 18 & 47 & 35 & 100 & 6.68 \\
\hline $\begin{array}{l}\text { Provides guidelines for formation of conservation } \\
\text { associations to promote rights of conservancies in the } \\
\text { ecosystem. }\end{array}$ & 19 & 42 & 39 & 100 & 6.31 \\
\hline $\begin{array}{l}\text { Provides guidelines for management planning for the } \\
\text { ecosystem }\end{array}$ & 24 & 47 & 29 & 100 & 6.4 \\
\hline Average & 19 & 48 & 33 & 100 & 6.4 \\
\hline
\end{tabular}

Source: Fieldwork, August 2013

Overall, findings indicate that respondents perceived that Kenyan policy and governance practices support community participation wildlife conservation to a moderate extent with a composite mean score was $6.4(4.0 \leq \mathrm{ME}<7.9)$ out of a possible 10. This study shows that 16 percent, 54 percent and 30 percent of the respondents perceived that Kenyan policy and governance practices support formation and operation of group ranches to a low, moderate and high extent respectively. The mean score was $6.94(4.0 \leq \mathrm{ME}<7.9)$ indicating that that Kenyan policy and governance practices support wildlife conservation in the Amboseli ecosystem but to a moderate extent. Table 7 reveals that Kenyan policy and governance practices provides guidelines for establishment of community conservancies, provides framework for lease agreements for land management structures in the ecosystem, provides guidelines for establishment of eco-tourism ventures, provides guidelines for formation of conservation associations to promote rights of conservancies in the ecosystem, provides guidelines for management planning for the ecosystem but to a moderate extent as the mean scores were within this range $(4.0 \leq \mathrm{ME}<6.9)$ equivalent to was equivalent to 4.0 to 7.9 on the Likert scale. This implies that there is a perception that the national policy framework does not conclusively provide guidance for making wildlife conservation a viable land use option. However, this confirms guidelines contained in Sessional paper No 3 of 1975, (Republic of Kenya 1975) which provides for a shift in wildlife conservation policy that is intended to harmonize conservation with economic and social development. Despite these provisions, the government has never implemented them since enactment. As a result, the local community perceives wildlife conservation programmes as lacking the requisite policy directions to guarantee optimal benefits for their continued coexistence with wildlife in the region. This therefore calls for an integrated and adaptive ecosystem management approach to sustain wildlife and habitat diversity by empowering the local community to take control of their natural resource, secure their livelihoods and protect their communal land and environment.

To examine the relationship between Kenyan wildlife policies and legal framework and community participation in wildlife conservation, the Pearson's Product moment correlation, which is a non-parametric measure of the strength and direction of association that exists between two variables, was used to measure and the results were as shown in Table 5. 
Table 5: Relationship between Kenyan policy and legal framework and Community Participation in Wildlife Conservation

\begin{tabular}{lcc}
\hline & & Community Participation in Wildlife Conservation \\
\hline $\begin{array}{l}\text { Kenyan policy and legal } \\
\text { framework }\end{array}$ & Pearson Correlation & $0.339 * *$ \\
& Sig. 2-tailed & .000 \\
& $\mathrm{~N}$ & 100 \\
\hline
\end{tabular}

** Correlation is significant at the 0.01 level 2-tailed.

From the correlations presented in Table 5, Kenyan wildlife policies and legal framework $(\mathrm{r}=0.339, \mathrm{P}<.01)$ yielded moderate and significant positive relationships with community participation in wildlife conservation. This implies that the existing Kenyan wildlife policies and legal framework moderately influence community participation in wildlife conservation. To confirm the nature of the relationship between Kenyan wildlife policies and legal framework and community participation in wildlife conservation, a regression analysis was done and the results are presented in Table 9.

Table 6: Regression results for Kenyan policy and legal framework and Community Participation in Wildlife Conservation

\begin{tabular}{|c|c|c|c|c|c|c|c|c|}
\hline \multirow{2}{*}{\multicolumn{2}{|c|}{ Model }} & \multicolumn{2}{|c|}{$\begin{array}{l}\text { Unstandardized } \\
\text { Coefficients }\end{array}$} & \multirow{2}{*}{$\begin{array}{c}\text { Standardized } \\
\text { Coefficients } \\
\text { Beta }\end{array}$} & \multirow[t]{2}{*}{$\mathbf{T}$} & \multirow[t]{2}{*}{$\mathbf{R}$} & \multirow[t]{2}{*}{$\mathbf{R}^{2}$} & \multirow[t]{2}{*}{ p-value } \\
\hline & & B & Std. Error & & & & & \\
\hline 1 & (Constant) & 2.332 & 0.085 & & 27.455 & & & .000 \\
\hline & $\begin{array}{l}\text { Kenyan policy and } \\
\text { legal framework }\end{array}$ & 0.134 & 0.041 & 0.198 & 3.265 & 0.362 & 0.131 & 0.001 \\
\hline
\end{tabular}

Dependent Variable: Community Participation in Wildlife Conservation

From the findings, Kenyan wildlife policies and legal framework moderately influences community participation in wildlife conservation in the ecosystem. The regression results (Table 9) showed that provisions in the Kenyan wildlife policies and legal framework have a direct effect upon community participation in wildlife conservation in the ecosystem with a positive standardized beta coefficient (0.198). The results show that 13.1 percent $\left(\mathbf{R}^{2}=0.131\right)$ of the variation in community participation in wildlife conservation in the ecosystem is explained by provisions in the Kenyan wildlife policies and legal framework. Analysis of these findings indicate that implementation of the Kenyan wildlife policies and legal framework would encourage community participation in wildlife conservation $(\mathrm{T}=3.265)$.

\section{Incentives for enhanced community participation and securing more space for wildlife conservation}

The third and final specific objective of this study was to identify incentives for enhanced community participation and securing more space for wildlife conservation in the Amboseli ecosystem based on recommended wildlife utilization options (Table 10), equitable sharing of benefits from wildlife conservation (Box 1) and options for creating more space for wildlife conservation (Table 7).

Table 7: Recommended Wildlife Utilization Options

\begin{tabular}{|c|c|c|c|c|}
\hline \multirow{2}{*}{ Wildlife Utilization Options } & \multicolumn{4}{|c|}{$\begin{array}{l}\text { Percentage } \\
\end{array}$} \\
\hline & Low & Moderate & High & Total \\
\hline Revenue sharing from government controlled Park & 10 & 12 & 72 & 100 \\
\hline Community Sanctuary & 16 & 16 & 68 & 100 \\
\hline Traditional uses & 17 & 39 & 44 & 100 \\
\hline Cultural Manyatta's & 12 & 26 & 62 & 100 \\
\hline Lodge and Camps & 24 & 43 & 33 & 100 \\
\hline Hunting & 95 & 0 & 5 & 100 \\
\hline
\end{tabular}

Source: Fieldwork, August 2013

From Table 10, majority of the respondents (72 percent) considered revenue sharing from the government controlled Park as the most viable option to utilize wildlife in the area. Community sanctuaries and cultural manyattas were cited by 68 percent and 62 percent of the respondents respectively. This study concurs that community sanctuaries and establishment cultural Manyatta's are determinants in individuals' coexistence with wildlife as they collectively create a tourism package in the ecosystem. Development of lodges and camps is moderately recommended by 43 percent of the respondents as an option for wildlife utilization in the area. The lodges and camp sites that dot the ecosystem thrive because of the wildlife conservation initiatives in the Amboseli National Park and the surrounding group ranches. It is worth noting that hunting was the less option recommended as an option for wildlife utilization in this area. This implies that with proper land use policies in the area, the local community would like to continue having wildlife on their lands 
Analysis of the qualitative data indicated that the respondents asserted the need for Amboseli park management to disseminate information on revenues generated from Amboseli and the expenditures in running the park for appreciation of the benefits and costs of conservation in the ecosystem. It was further revealed that initiated projects by the government and other conservation NGO's are implemented without knowledge of the entire community and thus proceeds from land leases benefits a few. With proper communication, all community members will believe in the conservation crusade as they will collectively share the accruing benefits /costs of wildlife conservation in the ecosystem.

Table 8: Options for Creating More Space for Wildlife Conservation

\begin{tabular}{|c|c|c|c|c|c|}
\hline \multirow{2}{*}{ Options for More Wildlife Space } & \multicolumn{4}{|c|}{ Percentage } & \multirow{2}{*}{ Mean Scores } \\
\hline & Low & Moderate & High & Total & \\
\hline $\begin{array}{l}\text { Adopt land use practice compatible with wildlife } \\
\text { conservation }\end{array}$ & 9 & 12 & 79 & 100 & 8.26 \\
\hline $\begin{array}{l}\text { Enumerate the Benefits/liabilities of wildlife outside } \\
\text { Amboseli }\end{array}$ & 8 & 13 & 79 & 100 & 8.21 \\
\hline $\begin{array}{l}\text { Enabling Institutional arrangements that enhance } \\
\text { wildlife conservation }\end{array}$ & 18 & 24 & 58 & 100 & 8.01 \\
\hline Enhanced Benefit sharing and community rights & 4 & 21 & 75 & 100 & 8.24 \\
\hline $\begin{array}{l}\text { Adoption of land use plan which guide land use types } \\
\text { within certain areas }\end{array}$ & 14 & 29 & 57 & 100 & 8.13 \\
\hline
\end{tabular}

Source: Fieldwork, August 2013

From Table 8, adopting land use practices compatible with wildlife conservation, enumerating benefits/liabilities of wildlife outside Amboseli, enabling institutional arrangements that enhance wildlife conservation, enhanced benefit sharing and community rights and adoption of land use plan which guide land use types within certain areas are highly recommended measures for creating more space for wildlife conservation in the Amboseli ecosystem as the mean scores were within this range $(8.0 \leq \mathrm{ME}<10.0)$ equivalent to was equivalent to 8.0 to 10.0 on the Likert scale. It was established that more space for wildlife conservation is required so as to secure the ecosystem for sustainability to provide resilience to critical ecosystems as well as species as climate change and climate variability poses new threats. This calls for an integrated and adaptive ecosystem management approach to sustain wildlife and habitat diversity by empowering the local community to take control of their natural resource, secure their livelihoods and protect their communal land and environment.

These findings supports those by [5] that rights of indigenous people such as rights to development and equal benefit sharing including rights to determine the development or use priorities and strategies on their lands, territories and resources and to benefit equitably from conservation and sustainable use of such areas are often particularly relevant for conservation and sustainable use of natural resources. Findings indicated that that livestock production has a significant compatibility with wildlife conservation in the Amboseli ecosystem. Findings in Table 11 support assertions by [6] that enhancing equitable sharing is key in securing more space for wildlife conservation and this calls for adoption of policies that that can necessitate development of marketing facilities for livestock, providing security against raids from wildlife, retain rights to graze an agreed number of livestock in the government controlled park. This in effect confirmed that coexistence between Maasai pastoral culture and wildlife in the ecosystem for over a long time and that livestock production is more compatible as it is easier to manage and integrate with wildlife [7].

\section{Conclusions}

The communities living around ANP will seek to experience a sense of reciprocation through their involvement in conservation activities to ensure that they receive reasonable returns for leasing or putting easements on their land for wildlife use only, while the conservation agencies have to ensure that payment for easement and leases is sustained. Results from this study shows that, human activities within the Amboseli ecosystem have led to widespread habitat fragmentation, reduction in wildlife distribution range, shrinking of dry season dispersal areas, blockage of migratory route/corridors and increased human-wildlife conflicts due to competition for resources such as water, forage and space. The vast areas of pristine wildlife habitats have been lost or degraded as a result of land subdivisions to individual private properties and conversion of rangelands to crop cultivation and subsistence use. In other cases, uncoordinated fences have been erected that have created barriers to seasonal movements of animals. Consequently, the ecological limitation of the ecosystem calls for the management of wildlife resource in an inclusive manner involving the local communities.

This study makes a number of recommendations for policy that need to be put on place to enhance community participation in wildlife conservation and win more space for wildlife conservation. The study has also made recommendations on areas that more research need to be undertaken on. 


\section{Recommendations}

While the Government has accepted community participation approaches in the management of natural resources that provide rural communities with secure tenure of their natural resources, the commitment to develop appropriate supporting legislation and technical capacity has been lacking. In fact, even where legislation is in place, rights of access to and use of natural resources have not been clearly defined. Communities have not received the necessary assistance to develop capacity to independently carry out their conservation activities. The result is that communities are unable to realize the optimal benefits from the wealth of resources on their lands.

A significant proportion of the Maasai community concurred that wildlife is beneficial to them. This study however found out that some respondents had not fully associated wildlife with any benefits for their livelihoods despite evidence that wildlife had contributed to the economic status of the region. This study recommends increase in public education awareness on conservation and wildlife management matters and also emphasizes the need for consultations with and the consent of landowners when designating areas that need protection as wildlife dispersal areas or migratory routes/corridors within their properties

\section{Participation of Local People in Conservation and Management of Wildlife Resource}

The drive for the local people to control and benefit from wildlife resource within their areas of jurisdiction is now widely accepted concept for managing protected areas in many parts of the world. In Amboseli, wildlife constitutes important natural resource that must be conserved and managed by people in partnership with government and private sector. It is in recognition of this fact that the proposed [8] strongly articulates the need for the participation of local people in the management and conservation of wildlife resource. It is therefore imperative that the management of the wildlife resource in the ecosystem has to be inclusive and involve the local communities. Decentralized wildlife resource management is key to sustainable development and equitable benefit sharing arrangement. In order to meet the conservation goals and local community's livelihood needs, the increase of public education and awareness on conservation and wildlife management is critical.

\section{Operationalize Land management Acts}

Policies and legislation such as the Land Use Policy and the draft Land Act (2012), the draft Land Registration Bill (2012), Wildlife Conservation and Management Draft Bill (2013) should be used to secure conservation areas through easements, leases, outright purchase by the government or other organization, as well as use of economic instruments that ensures payment for ecosystem services.

\section{Establishment of Ecotourism Ventures}

To protect wildlife outside the Amboseli Park, measures for the establishment of more community based conservation projects such as creation of communal conservancies must be explored. Communal conservancies could be a mitigation measure of the current and ongoing land subdivision in Amboseli. Communal conservancies would perhaps be a way of managing wildlife outside the park where a group of legally constituted pastoralists could be encouraged to pool their individual land resources together to manage and benefit from wildlife and tourism on their communal land.

Throughout the group ranches now, ecotourism investments have provided income and employment opportunities, which have led to improved infrastructure and more positive local attitudes towards wildlife. Community wildlife sanctuaries and other ecotourism ventures that provide direct benefits in the areas adjacent to ANP need to be developed in addition to establishment of buffer zones through formation of conservancies and sanctuaries to reduce undesirable human activities (poaching, livestock grazing, settlements and agriculture). These ecotourism investments should be managed to reduce exploitation of the local communities and improve equitable distribution of tourism benefits with investors.

\section{Group Ranches Subdivision}

The current subdivision exercise that is taking place in the group ranches poses a threat to the future conservation of wildlife and pastoralism in Amboseli. Subdivision of land into smaller holdings will definitely impact on the wildlife dispersal areas of the park. A strategy must be devised for alleviating the negative impacts of subdivision. The community knows the areas where wildlife disperses into. It is imperative therefore that the communities be enabled and capacitated to come up with land use plans within the group ranches where wildlife areas will be zoned and reserved specifically as wildlife management areas

The findings and implications of this study are important in understanding the danger of insularization of Amboseli National Park. Urgent initiatives are needed if the Maasai group ranches are to remain viable wildlife dispersal areas. The expansion of clusters of human settlement and activity around the park could potentially close the existing wildlife movement routes into and out of the park. These dispersal areas are 
important in providing feeding and breeding sites, limiting resource competition, and maintaining genetic health of populations.

\section{Strengthening of Community Based Ecotourism to Promote Conservation}

Community based ecotourism is today accepted as one of the most proactive tools of managing and ensuring the future of wildlife resources. This becomes even more critical where protected areas border privately owned land and where such private land is used by wildlife as its habitat. In Amboseli the land in the group ranches serves as important wildlife habitats. Emphasis must focus on ensuring that the benefits of tourism are attained more significantly by the community. Strengthening community based enterprises will reduce dependency on KWS and local development partners. It will also ensure that wildlife is viewed in a more positive manner throughout the group ranches. The viability and future of wildlife especially on privately land will also be guaranteed. For the community to become an integral part of conservation efforts, they must reap the benefits of conservation. Eco-tourism enterprises constitute one such way of furthering conservation as well as development.

\section{Initiate Land Banking and Direct Land Purchases}

Land Banking for Conservation programs need to be effected in which land required for present and future needs is reserved to mitigate against fragmentation of wildlife habitats and degradation. Conservation organizations may lease land at market prices from landowners or group ranch members so that it may be set aside for wildlife. Outright land purchase for conservation using the Lake Nakuru Model in which KWS purchased land around Lake Nakuru and amalgamated it into the Deed Plan for the Lake Nakuru National Park.

\section{Funding Conservation Initiatives}

The study revealed that the land owners in Amboseli are interested in conservation. One problem that they are continually faced with is funding to support their conservation interests and activities. Donor funding to support these social development initiatives is needed in almost all the group ranches. The group ranches themselves must however devise their own initiatives for funding. The Amboseli ecosystem and the wildlife resources found therein is their heritage. The group ranches must play a significant role in protecting their own natural resources by establishing a Conservation trust which is nonprofit outfit that can qualify for donor funding if its main objects are to conserve wildlife and wildlife habitats for promotion of sustainable development. The establishment of a conservation trust by all the members of the group ranches will go a long way in promoting conservation.

\section{Enhanced Inter-departmental Linkages}

Successful interrelationship and coordination between the government departments dealing with land, environment and natural resources, wildlife and finance. A mechanism needs to be established to coordinate the efforts of the multiple actors towards securing of the priority corridors and for resource mobilization and accountability.

\section{Revised Revenue Sharing Formula}

The Commission for Revenue Allocation (CRA) in February 2012 released a formula to guide the horizontal share of revenues based on five parameters, namely population $(60 \%)$, equal share $(20 \%)$, poverty $(12 \%)$, land and infrastructure needs $(6 \%)$ and fiscal discipline (2\%). However, given that $12 \%$ of the country's GDP is accounted for by tourism, $70 \%$ of which comes from wildlife, it is therefore, imperative that communities who host and interact with wildlife on their lands should be considered by the national exchequer for resource allocation and revenue sharing as a reward for continued existence and conservation of wildlife for a sustained tourism sector.

\section{References}

[1]. Cernea, M. M. and Schmidt-Soltau, K. (2006), Poverty Risks and National Parks: Policy Issues in Conservation and Resettlement, World Development, Vol. 34 (10), 1808-1830.

[2]. Ntiati, P. (2002), "Group Ranches Subdivision Study in Loitokitok Division of Kajiado District," LUUCID Working Paper 7, Land Use Changes Impacts and Dynamics, (Nairobi ILRI,

[3]. Western, D. and Wright, R.M. (1994), Natural Connections: Perspectives in Community-based Conservation, Washington, D.C., Island Press Western.

[4]. Kenya Wildlife Service Strategic Plan 2008 -2012, Nairobi.

[5]. Springer, J.J., Campese, and M. Painter, (2011), Conservation and Human Rights - Key Issues in and Contexts, Scoping Issues for Conservation Initiative on Human Rights, CIFOR and IUCN: Bogor, Indonesia

[6]. Hulme, D. and Murphree, M.: 1999, 'Communities, wildlife and the "new conservation" in Africa', Journal of International Development 11(2), 277-285.

[7]. Campbell D.J., H. Gichohi, R. Reid, Mwangi, A. Chege, L. \& Sawin, T., (2003), "Interactions between people and wildlife in Southeast Kajiado District, Kenya", The Land Use Change, Impacts and Dynamics (LUCID) Project, Working Paper Series Number 18, International Livestock Research Institute (ILRI), Nairobi, Kenya, Website: hpp: / www. lucideastafrica.org

[8]. Kenya Wildlife Service Strategic Data Base 2012) 